\title{
Tailoring of YIG film properties via compositional tuning by multi-beam pulsed laser deposition
}

\author{
Alberto Sposito $^{1 *}$, Gavin B.G. Stenning ${ }^{2}$, Simon A. Gregory ${ }^{2}$, Katherine A. Sloyan ${ }^{1}$, Tina L. Parsonage ${ }^{1}$, \\ Otto Muskens ${ }^{2}$, Peter A.J. De Groot ${ }^{2}$, Robert W. Eason ${ }^{1}$
}

\author{
1)Optoelectronics Research Centre, University of Southampton, Southampton, SO171BJ, United Kingdom \\ 2)Physics and Astronomy, University of Southampton, Southampton, SO171BJ, United Kingdom \\ *e-mail:as11g10@orc.soton.ac.uk
}

\begin{abstract}
We report an investigation of the effects of variation of composition on the properties of YIG (yttrium iron garnet) films grown on YAG substrates by multi-beam pulsed laser deposition (PLD).
\end{abstract}

Magneto-optic garnets, such as $\mathrm{YIG}\left(\mathrm{Y}_{3} \mathrm{Fe}_{5} \mathrm{O}_{12}\right)$, find application in areas including optical communication, where they can be used as optical rotators and isolators [1] via their Faraday effect, and also in the microwave range, where their ferromagnetic properties can be exploited e.g. in magnetostatic wave band pass filters [2].

YIG films have been grown by liquid phase epitaxy [3], sputtering [4] or pulsed laser deposition (PLD) [2, 5]. Single-beam PLD from a stoichiometric target usually leads to films that are iron ( $\mathrm{Fe}$ ) deficient, as previously reported in the literature [2] and confirmed in our experiments [5].

We have studied the composition, analysed by energy-dispersive x-ray spectroscopy, and the effects of stoichiometric variation on the resultant properties of PLD-grown YIG films, whose yttrium (Y) and $\mathrm{Fe}$ concentration is varied by co-ablation of two separate targets of polycrystalline YIG with either a $\mathrm{Y}_{2} \mathrm{O}_{3}$ or a $\mathrm{Fe}_{2} \mathrm{O}_{3}$ target. In this report, we analyse in detail our results with the latter target, for which we have most extensive data.

All depositions were performed in our multi-beam PLD system, described in [6]. YIG films were grown on $10 \times 10 \mathrm{~mm}^{2} 1 \mathrm{~mm}$-thick YAG (100)-oriented substrates, heated to $T \approx 1400 \mathrm{~K}$, the highest temperature possible in our system, lower than the optimum value $\left(T_{\mathrm{OPT}} \approx 1600 \mathrm{~K}\right)$ for YIG/YAG growth [5]. The off-axis configuration of target holders relative to the substrate causes a lower deposition rate, compared to that reported in [5], using our single-beam PLD system; for this reason, we reduced the target-substrate distance to $d=4 \mathrm{~cm}$ and, at the same time, increased the oxygen pressure to $P_{\mathrm{O} 2}=3.4 \mathrm{~Pa}$, following the general rule of thumb: $d P_{\mathrm{O} 2}$ $=$ const., in order to maintain the same plume dynamics. Multi-PLD experiments of $\mathrm{YIG}+\mathrm{Fe}_{2} \mathrm{O}_{3}$ were performed with two different laser configurations, as described below.

Samples Y45 and Y48-51, whose data are reported in the upper half of Table 1, were deposited by ablating the YIG target with a frequency-quadrupled Nd:YAG laser (wavelength: $\lambda=266 \mathrm{~nm}$; fluence: $F \approx 1.3 \mathrm{~J} / \mathrm{cm}^{2}$; pulse repetition rate: $f=10 \mathrm{~Hz}$ ) and the $\mathrm{Fe}_{2} \mathrm{O}_{3}$ target with a KrF laser (wavelength: $\lambda=248 \mathrm{~nm}$; fluence: $F \approx 1.3$ $\mathrm{J} / \mathrm{cm}^{2}$ ), whose pulse repetition rate was varied between 0 and $4 \mathrm{~Hz}$ to increase the Fe concentration in the YIG films.

Samples Y52-58, whose data are reported in lower half of Table 1, were deposited by ablating the YIG target with the $\mathrm{KrF}$ laser (fluence: $F \approx 2.3 \mathrm{~J} / \mathrm{cm}^{2}$; pulse repetition rate: $f=20 \mathrm{~Hz}$, except for Y57, grown at $f=16 \mathrm{~Hz}$ ) and the $\mathrm{Fe}_{2} \mathrm{O}_{3}$ target with the Nd:YAG laser $\left(F \approx 1.3 \mathrm{~J} / \mathrm{cm}^{2}\right)$, whose pulses were gated through a programmable shutter, whose opening and closing times were changed to achieve equivalent repetition rates of $0-4 \mathrm{~Hz}$. The target ablation ratio $r$ is defined as the ratio of the number of laser pulses per second on the $\mathrm{Fe}_{2} \mathrm{O}_{3} \operatorname{target}$ over the number of laser pulses per second on the YIG target.

As shown in Figure 1, FMR (ferromagnetic resonance) linewidth tends to increase with increasing target ablation ratio and consequently with increasing Fe concentration, whatever laser system is used, although excimer ablation of YIG tends to produce better quality films: in fact, in spite of the higher Fe concentration, YIG films grown by ablating YIG with the KrF laser (Y48-51) have broader FMR linewidth than Y52-58, grown by ablating YIG with the excimer laser. Moreover, Y48-51 have darker colour, lower optical transmission, higher surface roughness and particulate density than Y52-57. Comparing the un-doped YIG films, Y45 and Y58, the latter (grown with the KrF laser) have narrower FMR linewidth than the former (grown with the Nd:YAG laser), but they are both uniform and smooth, unlike $\mathrm{Y} 48-51$; this means that it is the ablation of $\mathrm{Fe}_{2} \mathrm{O}_{3}$ that is critical for the production of smooth YIG films. In fact, deposition of pure $\mathrm{Fe}_{2} \mathrm{O}_{3}$ testers on $c$-cut, (0001)-oriented sapphire $\left(\alpha-\mathrm{Al}_{2} \mathrm{O}_{3}\right)$ substrates showed that ablation of $\mathrm{Fe}_{2} \mathrm{O}_{3}$ with the Nd:YAG laser produced crystalline hematite $\left(\alpha-\mathrm{Fe}_{2} \mathrm{O}_{3}\right)$ films with lower particulate density and surface roughness than PLD of $\mathrm{Fe}_{2} \mathrm{O}_{3}$ with the $\mathrm{KrF}$ laser. Optical spectroscopy showed that transmission decreases with increasing $\mathrm{Fe}$ concentration and a red-shift of the absorption edge occurs in Y52-58. 
Table 1. Target ablation ratio $r$, thickness $t$, composition, FMR linewidth $(H)$ and colour of YIG samples

\begin{tabular}{|c|c|c|c|c|c|c|c|}
\hline SAMPLE & $\boldsymbol{r}$ & $\begin{array}{c}t \\
{[\mu \mathrm{m}]}\end{array}$ & $\begin{array}{c}\text { Y concentration } \\
\text { [formula number] }\end{array}$ & $\begin{array}{l}\text { Fe concentration } \\
\text { [formula number] }\end{array}$ & Y/Fe & $\begin{array}{c}H \\
{[\mathbf{m T}]}\end{array}$ & Sample colour \\
\hline \multicolumn{8}{|c|}{ YIG samples grown by ablating the YIG target with the Nd:YAG laser and the $\mathrm{Fe}_{2} \mathrm{O}_{3}$ with the KrF laser } \\
\hline Y45 & 0 & 2 & 3.37 & 4.63 & 1.37 & 4.67 & Yellow \\
\hline Y48 & 0.1 & 1.4 & 3.10 & 4.89 & 1.58 & 17.25 & Orange \\
\hline Y49 & 0.2 & 1.8 & 3.02 & 4.98 & 1.65 & 21.12 & Light red \\
\hline Y51 & 0.3 & 1.7 & 2.93 & 5.07 & 1.73 & 24.05 & Dark red \\
\hline Y50 & 0.4 & 1.7 & 2.92 & 5.08 & 1.74 & 29.81 & Dark red \\
\hline \multicolumn{8}{|c|}{ YIG samples grown by ablating the YIG target with KrF laser and the $\mathrm{Fe}_{2} \mathrm{O}_{3}$ target with the Nd:YAG laser } \\
\hline Y58 & 0 & 2.5 & 3.50 & 4.50 & 1.28 & 3.87 & Yellow \\
\hline Y55 & 0.05 & 2.2 & 3.40 & 4.60 & 1.35 & 6.03 & Yellow \\
\hline Y52 & 0.1 & 3 & 3.22 & 4.78 & 1.48 & 6.50 & Dark yellow \\
\hline Y57 & 0.125 & 3 & 3.03 & 4.97 & 1.64 & 9.21 & Brownish / dark yellow \\
\hline Y54 & 0.15 & 4 & 2.88 & 5.12 & 1.78 & 8.70 & Light brown \\
\hline Y53 & 0.2 & 3.5 & 2.89 & 5.11 & 1.77 & 16 & Brown \\
\hline
\end{tabular}

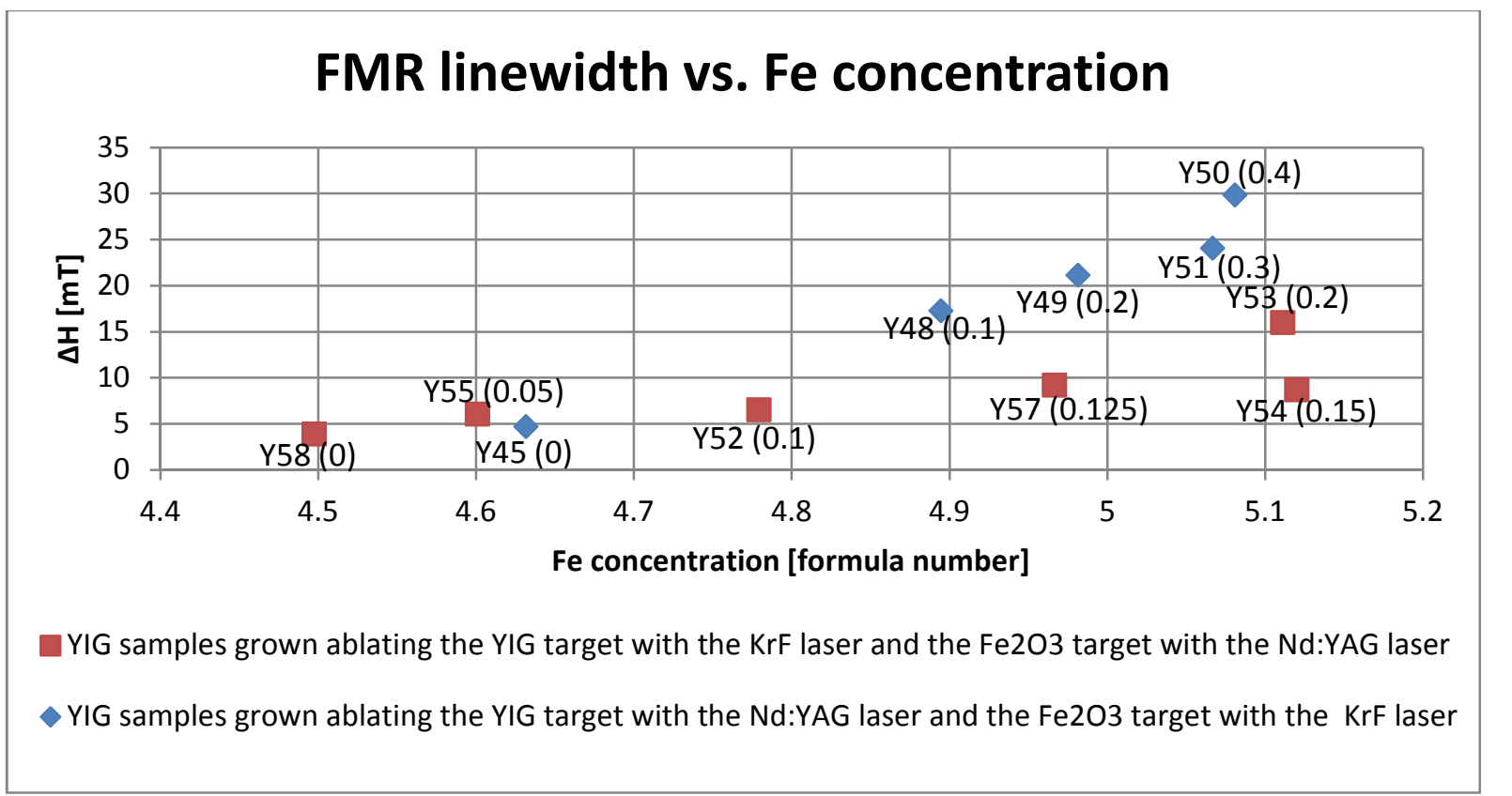

Fig. 1. Variation of FMR linewidth ( $H$ ) with Fe concentration - The number in parentheses is the target ablation ratio.

In conclusion, Fe-deficient YIG films seem to have better optical and magnetic properties. We are also currently depositing and characterising YIG samples grown by multi-PLD of YIG and $\mathrm{Y}_{2} \mathrm{O}_{3}$ : we suspect that yttrium doping may produce a reduction in FMR linewidth and an increase in optical transmission.

\section{References}

[1] H. Dotsch, N. Bahlmann, O. Zhuromskyy, M. Hammer, L. Wilkens, R. Gerhardt, P. Hertel, and A. F. Popkov, J. Opt. Soc. Am. B-Opt. Phys. 22, 240-253 (2005).

[2] S. A. Manuilov, R. Fors, S. I. Khartsev, and A. M. Grishin, J. Appl. Phys. 105, 033917 (2009).

[3] V. R. Sobol, T. V. Volchik, S. M. Arabei, B. V. Korzun, and N. A. Kalandab, J. Appl. Spectrosc. 76, 203-208 (2009)

[4] T. Boudiar, B. Payet-Gervy, M. F. Blanc-Mignon, J. Rousseau, M. Le Berre, and H. Joisten, J. Magn. Magn. Mater. 284, 77-85 (2004).

[5] A. Sposito, T .C. May-Smith, G. B. G Stenning, P. A. J. de Groot, and R. W. Eason, Opt. Mater. Express 3, 624-632 (2013).

[6] T. C. May-Smith, K. A. Sloyan, R. Gazia, R. W. Eason, Cryst. Growth Des. 11, 1098-1108 (2011) 